\title{
Effect of Nursing Management on Pin Site Infection Among Incidence Patients with External Fixators
}

\author{
Marwa Abd Elhamed Sayed ${ }^{1}$, Magda Ahmed Mohammed ${ }^{2}$, Khaled Mohammed Mostafa ${ }^{3}$ \& Amna Abdullah \\ Desouky ${ }^{4}$. \\ 1. Instructor in Medical - Surgical Nursing Department, Faculty of Nursing, Assiut University, Egypt. \\ 2. Professor of Medical-Surgical Nursing, Faculty of Nursing, Assiut University, Egypt. \\ 3. Professor of Orthopedic Surgery, Faculty of Medicine, Assiut University, Egypt. \\ 4. Lecturer of Medical-Surgical Nursing, Faculty of Nursing, Assiut University, Egypt.
}

\begin{abstract}
Background: Pin site infection is the most common complication of external fixator. Aim of the study: To evaluate the effect of nursing management on pin site infection incidence among patients with external fixators. Subjects and Methods: A sample of 80 patients (males and females) attended to the trauma department that their ages ranged from 18 to 65 years old, had open or closed fracture in lower and/or upper limbs that were indicated for external fixation application. The study was conducted in traumatology department at Assiut University Hospital. Tools: (I): Patient assessment sheet. Tools: (II) Checketts and Otterburn's Grading System. Results: Only four (5.0\%) patients developed pin site infection, whose grade was grade I. There was highly statistical significant relation between pin site infection and smoking p 0,001. Conclusion: After providing nursing management for patients with external fixators most of studied patients didn't develop pin site infection. Recommendation: Increase patients' awareness about the importance of pin site care and periodic check up to prevent developing any complications which can effect on their quality of life.
\end{abstract}

\section{Key Words: Nursing Management, Pin Site Infection \& External fixator.}

\section{Introduction}

Pin site infections are one of the most common complications associated with skeletal pins and wires. Infection may range from superficial to deep infection. $27.4 \%$ pin site infections was reported by Christopher \& Raymond, (2016). There are three levels for pin site infection; level one (Pin site reaction) represents normal/physiologic changes in skin color, skin warmth pin site drainage and resolves within $72 \mathrm{~h}$, level two (Pin site colonization) represents erythema, warmth, drainage, possible pain and positive culture, level three (Pin site infection) which represents all of the above, possibly with the addition of pus, pin loosening or increased microbial growth on cultures (Lioyd et al., 2008).

Risk factors for acquiring pin site infections may be due to a combination of factors related to patients or to external fixator. Patients' factors include age, smoking, medical conditions as diabetes, rheumatoid arthritis, collagen vascular diseases, immune status, some consumed medications as steroids and open wound, while factors related to external fixator include duration of pin fixator, operative technique and care given (Nikolas et al., 2016).

External fixator is surgical application of apparatus attached to percutaneous pins or wires that penetrate the bone and are attached to an external frame. It used to treat complex fractures, limb deformity and certain orthopedic problems. External fixator has many shapes as halo thoracic braces, Ilizarov fixators and unilateral fixators (Singh, 2016).

Advantages of external fixator are stabilization of fracture, increased patient comfort, facilitation of nursing care, free motion of adjacent joint, blood loss is decreased when used for pelvic fracture, facilitation of vascular, soft tissue reconstruction and pulmonary function will improve. While disadvantages of external fixator are; the equipment is expensive, infection rate is high, delayed union or malunion, pin loosening and joint stiffness may occur (Leonid, 2013).

Nurses play an important role for patients undergoing external fixator application. Preoperatively; the nurse should carefully assess the patients' condition, diagnostic test results should be reviewed the night before surgery, prepare skin under aseptic condition, remove hair around the operative site and administer preoperative medication as prescribed (Ignatavicius \& Workman., 2015).

Postoperatively; the nurses do routine postoperative care in addition to specific care to the affected side. Which include; observing vital signs, administering postoperative medications as ordered, elevating the limb, inspecting pin site for signs and symptoms of infection and provide care for wound. Before discharge; the nurses educate patients about signs and symptoms of infection, restrictions needed to protect the affected limb, pin site care, activity of 
daily living, medications and follow up visits (Ferreira \& Marais, 2012).

\section{Significance of the study}

During the researcher's training period at trauma department, it has been observed that patients with external fixators were at high risk for developing pin site tract infection and/or other complications, which then lead to higher prolonged hospitalization, increased costs and higher mortality rates. $27.4 \%$ pin site infections was reported by Christopher \& Raymond, (2016). Hence this study was carried out to test the effect of applying nursing management on incidence of infection among these patients.

\section{Aim of the study}

To evaluate the effect of nursing management on reducing pin site infection incidence among patients with external fixators.

\section{Hypothesis}

The incidence of pin site infection among patients with external fixators after implementation will be reduced.

\section{Subjects \& Methods \\ Research design}

This study pre experimental one shot case study design. A schematic representation of the design is displayed in figure 1 .

Nursing management $\mathrm{X}$

Post test

$\mathrm{O} 2$

Fig.1. Pre experimental one shot case study design.

Where $\mathrm{X}$ is the nursing management. $\mathrm{O} 2$ is the incidence of pin site tract infection among patients with external fixators.

\section{Setting}

This study was conducted at trauma department of Assiut University Hospital.

\section{Sample}

This study was included 80 patients (males and females) attended to the trauma department that their ages ranged from 18 to 65 years old, had open or closed fracture in lower and/or upper limb who were indicated for external fixation application. Patients who had comorbid conditions as (Diabetic mellitus, vascular disease and type III open wound fracture) were excluded from the study.

Note: The sample was calculated by using the following equation according to (Steven, Thompson, 2012) with confidence level at $95 \%$ and the flow rate of patients 100 cases in 6 months and sample was selected 80 cases.

$$
n=\llbracket \frac{N \times p(1-p)}{\left.\left.\llbracket N-1 \times\left(d^{2} \div z^{2}\right)\right]+p(1-p)\right]}
$$

$\mathrm{N}=$ total patient population size of 200 cases who applied external fixators at Assiut University Hospitals during year 2017-2018 by $n=200$

$\mathrm{Z}=$ confidence levels is 0.95 and is equal to 1.96

$\mathrm{D}=$ The error ratio is $=0.05$

$\mathrm{P}=$ The property availability ratio and neutral $=0.50$

Tools

Two tools were utilized to conduct this study:

Tool (I): Patient assessment sheet:

This tool was developed by the researcher based on national and international literatures review to assess patients' condition it was consisted of three parts:

Part (1): Demographic data: Such as (name, age, gender, marital status, level of education, occupation, and smoking).

Part (2): Medical data: This part was included (history taking, physical examination, and laboratory investigations).

Part(3):Patients' knowledge about pin site infection, this part assessed patients' knowledge regarding prevention and management of pin site infection

\section{Scoring system of tool I (part 3)}

This part consisted of fifteen open ended questions. Correct and wrong answers were scored as 1 and 0 respectively, leading to a total score ranged from 0 to 15 . Patients who obtained less than $60 \%$ were considered having unsatisfactory level of knowledge. While those who obtained more than $60 \%$ were considered having satisfactory level of knowledge.

Tool(II): Checketts \& Otterburn's Grading System (Checketts et al., 1993) This scale adopted to evaluate postoperative pin site infection. This scale consists of three grades for minor infections and three grades for major infections. Minor infection consists of grade I which includes, slight discharge, redness around the pins, grade II which includes redness of the surrounding skin, pain and tenderness in the soft tissue, discharge of pus, grade III which similar to grade II plus fail to improve with intensive local treatment and antibiotics. While major infection consists of grade IV which includes severe soft tissue involvement affecting more than one pin, associated loosening of the pin, and grade $\mathrm{V}$ resemble grade IV in addition to bone involvement, radiographs show osteomyelitis. Finally grade VI includes sequestrum formation within the bone and persistent sinus continue to develop

\section{Scoring system of tool II}

This scale has six grades, from grade I to III consider minor infections, while from grade IV to VI consider major infections. 
Nursing management for reducing pin site infection among patients with external fixators:

It developed by the researcher based on national and internatonal literatures review. It was implemented by the researcher in different times; before application of external fixator and after application of external fixator on individual basis according to patients' condition to prevent and control the development of pin site tract infection. It consisted of the following:

$>$ Brief introduction about external fixator.

$>$ Advantages, disadvantages, and complications of external fixator.

$>$ Nursing care about external fixator.

> Nursing instruction before discharge includes (pin site care, nutrition, activity daily living, medication, and follow up visit).

\section{Methods}

\section{Ethical considerations}

- An official permission from the general director of the hospital and the head of the Orthopedic Surgery Department were taken to facilitate the data collection. Confidentiality and anonymity of patients were assured through coding of all data.

- Oral consent obtained from patients or guidance who are willing to participate in the study.

\section{Preparatory phase}

This phase was started by reviewing of current, past, local and international related literatures in the various aspects of the problems using books, articles, periodicals, and magazines.

\section{Content validity}

Content validity was done by five expertise (medical staff from orthopedic and trauma department) \& (nursing staff) from the medical-surgical nursing field who reviewed the tools for clarity, relevance, comprehensiveness, and applicability. Minor modifications were required and correction was carried out accordingly. As for the reliability the tool were confirmed for consistency by cronbach's alph coefficient (alpha $=0.829$ ).

\section{Pilot study}

A Pilot study was conducted on $10 \%$ of sample ( 8 patients) who admitted to the trauma department of Assiut University Hospital to test the applicability and clarity of the tools. Patients included in the pilot study were excluded from the current study sample.

\section{Field work phase}

- Data were collected through the period from February 2018 to August 2018.

- An initial interview; the researcher introduced herself to initiate line of communication, explained the nature and purpose of the study for patients.
- After taking the patients' oral agreement for voluntary participation in the study, each patient was communicated personally by the researcher.

- Assessment was done for all patients during admission as base line data by using tool I (part 1, and part 2) which included demographic and medical data.

- Nursing management was prepared in the form of booklet which given to each patient in a clear arabic language; also the researcher used pictures to enhance patients' understanding.

- Most patients received nursing management before application of external fixator, while a few number of patients received nursing management after application of external fixator because they admitted to emergency trauma department in night shift and medical decision regarding these cases was urgent immobilization.

- Patients' families had been involved to ensure patient support and facilitate achieving the goals.

- The researcher explained and applied the nursing management in three sessions. Each session time ranged from 20 to 30 minutes and including 5 minutes for discussion and feedback. The contents of each session were as follow:

First session: This session was implemented the day before application of external fixator, it started by introducing the researcher self to the patients telling them; aim of the meeting, orient patients regarding nursing management. Contents of this session included; brief introduction about external fixator, definition, advantages, disadvantages, complications of external fixator, and specific care about affect limb. This session ended by a summary of its content and feedback from the patient.

Second session: This session was implemented on the second day after application of external fixator, it stared by summery about what has been discussed in a previous session, objectives of the new session: It handled two topics: The first topic was; pin site care which mainly focused on dressing procedure that was done by researcher using betadine solution only once per day. Frequency of dressing during the period of hospitalization varied between patients according to patients' condition. The second topic was exercises in which the researcher demonstrated it in front of patient. Complete explanation of these exercises and dressing procedure were documented in the booklet. This session ended by a summary of its content and feedback from the patient. Most patients were cooperative and interested in a given topic and asked to continue the nursing management.

Third session: This session was implemented in the day before discharging from the hospital it stared by summary about what has been discussed in a 
previous session, objectives of the new session, content of this session; instructions that patients must follow it that are specific to care of pin site, diet, activity of daily living, mobility, exercises with external fixator, and medications. This session ended by a summary of its content and feedback from the patients through discussion and asking questions.

- The researcher arranged with the patients the time and place for follow up according to follow up visit in outpatient clinic of orthopaedic department at Assiut University Hospital.

- The researcher ensured patients' commitment to implement the nursing management weekly by telephone.

- Most patients discharged with external fixator in their affected side. A few number of patients removed it where they still in hospital waiting for another surgery as they were having associated injuries.

- Duration of external fixator removal varied between patients according to their condition.

Evaluation phase

- Evaluation of sites of pin insertion for all studied patients was carried out once in the time of removal of external fixator through using tool I (part 3) and tool II in Orthopaedic Outpatient Clinics.

\section{Statistical design}

Data entry and analysis were done using SPSS version 22 (Statistical Package for Social Science). Data were presented as frequency, percentage, mean, and standard deviation. A probability level of 0.05 was adopted as a level of significance for testing the research question.

\section{Result}

Table(1): Frequency distribution of demographic characteristics of studied patients $(n=80)$.

\begin{tabular}{|c|c|c|}
\hline Demographic characteristics & $\mathbf{N}$ & $\%$ \\
\hline \multicolumn{3}{|l|}{ Age (years) } \\
\hline $18<30$ & 39 & 48.8 \\
\hline $30<40$ & 19 & 23.8 \\
\hline $40<50$ & 7 & 8.8 \\
\hline $50<60$ & 6 & 7.5 \\
\hline $60: 65$ & 9 & 11.3 \\
\hline $33.83 \pm 14.59$ & & \\
\hline \multicolumn{3}{|l|}{ Sex } \\
\hline Male & 70 & 87.5 \\
\hline Female & 10 & 12.5 \\
\hline \multicolumn{3}{|l|}{ Marital status } \\
\hline Single & 32 & 40.0 \\
\hline Married & 48 & 60.0 \\
\hline \multicolumn{3}{|l|}{ Educational level } \\
\hline Illiterate & 28 & 35.0 \\
\hline Read and write & 12 & 15.0 \\
\hline Secondary education & 36 & 45.0 \\
\hline University & 4 & 5.0 \\
\hline \multicolumn{3}{|l|}{ Occupation } \\
\hline Office work & 4 & 5.0 \\
\hline Student & 6 & 7.5 \\
\hline Manual work & 62 & 77.5 \\
\hline Non-working & 8 & 10.0 \\
\hline \multicolumn{3}{|l|}{ Smoker } \\
\hline Yes & 16 & 20.0 \\
\hline No & 64 & 80.0 \\
\hline
\end{tabular}


Table (2): Frequency distribution of sites and grades of fractures among studied patients $(\mathrm{n}=\mathbf{8 0})$.

\begin{tabular}{|c|c|c|}
\hline Grades and sites of fracture & $\mathbf{N}$ & $\%$ \\
\hline \multicolumn{3}{|l|}{ Open grade I fracture (OGI\#) } \\
\hline OGI\# wrist & 1 & 1.3 \\
\hline OGI\# tibia & 3 & 3.8 \\
\hline OGI\# tibia and fibula & 4 & 5.0 \\
\hline OGI\# femur & 3 & 3.8 \\
\hline OGI\# pilon and tibia & 5 & 6.3 \\
\hline \multicolumn{3}{|l|}{ Open grade II fracture (OGII\#) } \\
\hline OGII\# tibia & 9 & 11.3 \\
\hline OGII\# fibula & 1 & 1.3 \\
\hline OGII\# tibia and fibula & 21 & 26.3 \\
\hline OGII\# femur & 9 & 11.3 \\
\hline OGII\# femur and tibia & 10 & 12.5 \\
\hline \multicolumn{3}{|l|}{ Other fracture } \\
\hline Fracture pelvis & 2 & 2.5 \\
\hline Dislocation of knee & 1 & 1.3 \\
\hline Fracture ankle & 11 & 13.8 \\
\hline
\end{tabular}

Table (3): Frequency distributions of associated injuries and data pertaining to external fixator among studied patients $(\mathbf{n}=\mathbf{8 0})$

\begin{tabular}{|c|c|c|}
\hline Associated injury, data pertaining to external fixator & $\mathbf{N}$ & $\%$ \\
\hline \multicolumn{3}{|l|}{ Associated injuries } \\
\hline Yes & 33 & 41.3 \\
\hline No & 47 & 58.8 \\
\hline \multicolumn{3}{|l|}{ Types of fixators } \\
\hline Unilateral frame & 57 & 71.3 \\
\hline Bilateral frame & 23 & 28.8 \\
\hline \multicolumn{3}{|l|}{ Site of fixators } \\
\hline Upper limb & 1 & 1.3 \\
\hline Lowe limb & 79 & 98.8 \\
\hline \multicolumn{3}{|l|}{ Number of pins } \\
\hline 2 pins & 2 & 2.5 \\
\hline 3pins & 16 & 20.0 \\
\hline 4pins & 51 & 63.8 \\
\hline 5pins & 7 & 8.8 \\
\hline 7 pins & 2 & 2.5 \\
\hline 8pins & 2 & 2.5 \\
\hline \multicolumn{3}{|l|}{ Duration of fixation } \\
\hline $10<30$ days & 28 & 35 \\
\hline $30<40$ days & 13 & 16.25 \\
\hline $40<50$ days & 16 & 20 \\
\hline $50<60$ days & 5 & 6.25 \\
\hline$>60$ days & 18 & 22.5 \\
\hline
\end{tabular}


Table(4): Frequency distribution of pin site tract infection according to grading system $(\mathrm{n}=80)$.

\begin{tabular}{|c|c|c|}
\hline Total pin site infection & $\mathbf{N}$ & $\%$ \\
\hline Yes & 4 & 5.0 \\
\hline No & 76 & 95.0 \\
\hline \multicolumn{3}{|l|}{ Pin site infection grading system: } \\
\hline \multicolumn{3}{|l|}{ Minor grades } \\
\hline Grade 1 & 4 & 5.0 \\
\hline Grade 2 & 0.0 & $0.0 \%$ \\
\hline Grade 3 & 0.0 & $0.0 \%$ \\
\hline \multicolumn{3}{|l|}{ Major Grades } \\
\hline Grade 4 & 0.0 & $0.0 \%$ \\
\hline Grade 5 & 0.0 & $0.0 \%$ \\
\hline Grade 6 & 0.0 & $0.0 \%$ \\
\hline
\end{tabular}

Table (5): Frequency distribution of total patients' knowledge regarding pin site care and pin site infection prevention $(\mathbf{n}=\mathbf{8 0})$.

\begin{tabular}{|l|c|c|}
\hline \multicolumn{1}{c|}{$\begin{array}{c}\text { Patients' knowledge } \\
\text { (time of external fixator removal) }\end{array}$} & \multicolumn{2}{c|}{ Posttest } \\
\cline { 2 - 3 } & $\mathrm{N}$ & $96.3 \%$ \\
\hline Satisfied & 77 & $3.8 \%$ \\
\hline Unsatisfied & 3 & $100.0 \%$ \\
\hline Total & 80 & \\
\hline
\end{tabular}

Table (6): Relation between pin site infection and demographic characteristics of studied patients $(\mathrm{n}=\mathbf{8 0})$

\begin{tabular}{|l|c|c|}
\hline \multirow{2}{*}{\multicolumn{1}{c|}{ Demographic characteristics }} & \multicolumn{2}{c|}{ Pin site infection } \\
\cline { 2 - 3 } & Pearson R. & P. Value \\
\hline Age & .072 & .528 \\
\hline Education level & .024 & .833 \\
\hline Occupation & $-.040-$ & .727 \\
\hline Gender & $-.076-$ & .508 \\
\hline
\end{tabular}

Table (7): Relation between pin site infection and external fixator variables among studied patients (n=80)

\begin{tabular}{|l|c|c|}
\hline \multirow{2}{*}{\multicolumn{1}{c|}{ External fixator variables }} & \multicolumn{2}{c|}{ Pin site infection } \\
\cline { 2 - 3 } & Pearson R. & P. Value \\
\hline Medical diagnosis & $-.075-$ & .511 \\
\hline Smoking & .395 & $0.001 * * *$ \\
\hline Length of stay & $-.080-$ & .481 \\
\hline Types of fixators & .018 & .872 \\
\hline Site of fixators & .022 & .844 \\
\hline Number of pins & $-.082-$ & .472 \\
\hline Duration of fixation & $-.037-$ & .746 \\
\hline Follow up visits & .181 & .142 \\
\hline Total patients' knowledge & $-.283-*$ & .011 \\
\hline
\end{tabular}

*. Correlation is significant at the 0.05 level (2-tailed)

Table(1): Illustrates that; about half of the studied patients $(48.8 \%)$ their age ranged from eighteen to below thirty with mean \pm SD $33.83 \pm 14.59$. Regarding sex it was found that majority $(87.5 \%)$ of studied patients were males, and more than half $(60.0 \%)$ of them were married. Regarding level of education less than half $(45.0 \%)$ of studied patients had secondary education. Regarding occupation; it was found that the work of majority of studied patients $(77.5 \%)$ was manual work. Also, this table shows that the majority $(80,0 \%)$ were non smokers.

Table (2): Reflects that, the highest percentage of patients had open grade II fracture mixed tibia and 
fibula, femur and tibia, tibia, femur, and ankle $(26.3 \%, 12.5 \%, 11.3 \%$, and $13.8 \%$ respectively).

Table (3): Demonstrates that, in addition to fracture there were $33(41.3 \%)$ of studied patients had associated injuries. Regarding to data pertaining to external fixator; more than two third of studied patients $(71.3 \%)$ applied unilateral frame and its site in their lower limb (98.8\%). Regarding number of fixator pins; more than half $(63.8 \%)$ of studied patients had four fixator pins and more than one third of the studied patients (35\%) applied the fixator for period from $10<30$ days.

Table (4): Reveals that only four (5.0\%) patients developed pin site infection, whose grade was grade I.

Table (5): Shows that, majority of patients (96.3\%) had satisfactory level knoweldege regarding pin site care and pin site tract infection prevention at the time of external fixator removal.

Table (6): Illustrates that, there were no significant relations between pin site infection and patients' age and educational level $\mathrm{p}>0,05$. Also, this table shows that, a negative correlation has been found between pin site infection and patients' occupation, and their gender.

Table (7): Illustrate that, there was highly statistical significant relation between pin site infection and smoking $\mathrm{p}<0,001$. While there were no significant relations between pin site infection and types of fixators, site of fixators, and follow up visit $p>0,05$. Also, this table shows that, a negative correlation has been found between pin site infection and medical diagnosis, length of stay, number of fixator pins, duration of fixation, and total patients' knowledge about pin site infection.

\section{Discussion}

Based on the results of the present study showed that; about half of the studied patients their age ranged from eighteen to below thirty. In the researchers' point of view, this is because most of the studied patients were at a young age that culturally has more access to be out of homes and are more engaged in high risky behaviors. These study findings were in the same line with a study conducted by Khorais et al., (2018) which shows that the mean age of the patients was thirty years.

Similar to these study findings, a study conducted by Mohamed et al., (2017) who stated that the median age of the patients with external fixation was thirty two years.

The present study showed that; majority of studied patients were males. This study finding was supported by Moneur (2013) who found that the higher incidence of fracture was among males than females.
Babis et al., (2011), also confirmed that more than half of studied patients were males.

As regards to occupation, it was found the work of majority of studied patients was manual work. This finding was congruent with Khorais et al., (2018) which showed that the works of more than half of the studied patients were manual workers too.

According to sites and grades of fracture the present study revealed that; the highest percentage of patients had open grade II fracture mixed tibia and fibula, femur and tibia, tibia, femur, and ankle. This study finding was agreeing with a study done by Mohammed et al., (2017) entitled, "Pin tract infection after uniplanar external fixation of open fractures at national teaching and referral hospital. Which revealed that the most common diagnoses of patients recruited was open tibia-fibular fracture.

The present study revealed that; in addition to fracture there were thirty three of studied patients had associated injuries. This study finding was in agreement with Golubović et al., (2016) who stated that there was thirty patients in their study had multiple injuries.

Regarding data pertaining to external fixator the results of the present study revealed that; majority of studied patients applied unilateral frame in their lower limb. This study finding was in agreement with Mahdian et al., (2017) who stated that lower extremity fractures were the most common fracture among motorcyclists.

Regarding number of fixator pins; more than half of studied patients had four fixator pins and more than one third of the studied patients applied the fixator for period from ten to less thirty days.

These study results disagreed with Rahşan et al., (2014) who carried out study entitled: "Effects of two different solutions used in pin site care on the development of infection". Which revealed that; the range of fixator pins was between four to eleven.

The study findings are in the same line with study conducted by Ramos et al., (2013) who stated that the fixator was removed after a median period of sixteen weeks.

Similar to the present study Amanti et al., (2010) who revealed that; the majority of patients' fractures in their study were in the lower limb and average pin implantation time was fourty five days.

Regarding to pin site tract infection according to grading System the present study revealed that, only four patients developed pin site infection, whose grade was grade I. This positive outcome may be due to the better nursing management that those patients received in this study. These findings are in the same line with a study conducted by Lee et al., (2012) entitled: "Antimicrobial gauze as a dressing reduces pin site infection: a randomized controlled 
trial". Which revealed that; pin site infection rate was lower in patients with a polyhexamethylene biguanide dressing as compared to dry gauze, only eleven patients developed pin site infection, whose grade was grade I and II, no deep infections occurred. According to patients' knowledge about pin site infection the present study revealed that; the majority of the studied patients had good level of knowledge regarding care that they should follow to prevent pin site tract infection. This study finding was in same line with a study conducted by Brereton (2016) who confirmed that patients with external fixation, their skills improved regarding pin site care after education.

Similar to these study findings a study conducted by Matt-Hensrud et al.,(2015) who stated that there was a statistical significance change in patients' knowledge three months following participation in discharge planning education.

Also similar to the present study finding, a study conducted by Khorais et al., (2018) who noticed that no one of patients included in the study had satisfactory level of self-care practices regarding the wound/pin site care, neurovascular integrity assessment, and practicing range of motion exercises at preprogram implementation with significant improvement which had been observed immediately after program implementation and in follow up.

The present study revealed that; the majority of studied patients were nonsmokers. This study finding was agreeing with a study done by Alemdaroglu et al., (2009) which revealed that; more than half of studied patients were nonsmokers.

The present study revealed that; there was highly statistical significant relation between pin site infection and smoking. This study finding was congruent with Suresh et al., (2008) who found that smokers tend to have higher pin site infection rate than nonsmokers, as there was statistically significant relation between pin site infection and smoking.

Also the present study revealed that; there were no significant relation between pin site infection and patients' age, educational level, types of fixators, site of fixators, and follow up visit. These study findings are in agreement with Moola et al., (2014) who found that location of injury, fracture classification, and patient demographics were not significantly associated with the development of infectious complications.

The present study revealed that; there were negative correlations had been found between pin site infection and patients' occupation, their gender, medical diagnosis, and patients knowledge. Also this study found negative correlation between pin site infection and length of stay, number of fixators pins, and duration of fixation. Which means that; as the length of stay, number of fixator pins, duration of fixation are decreased the percentage of patients who didn't have pin site infection are increased. Also, as the patients' knowledge is increased, the percentage of pin site infection is decreased.

These study finding were not in agreement with a study done by Laible et al., (2012). Which revealed that, there was no correlation seen between infection and classification of fracture, sex of the patient, age of the patient, or healing status of the fracture.

\section{Conclusion}

Based on the result of the present study, it can be concluded that: After providing the nursing management for studied patients only four patients developed pin site infection.

\section{Recommendations}

Based on the findings of the present study, the following recommendations are derived:

1. Nurses should be aware of instructions that should be given to patients with external fixators before discharge and inform patients about them.

2. Increase patients' awareness about the importance of pin site care and periodic check up to prevent developing any complications which can effect on their quality of life. Also Providing written nursing instruction booklet is of a great importance for patients.

3. Replication of the study on a large probability sample acquired from different geographical area in Egypt to figure out the main aspects of this problem.

\section{References}

1. Alemdaroglu K., Tiftikci U., Iltar S., (2009): Factors affecting the fracture healing in treatment of tibial shaft fractures with circular external fixator. Injury 2009;40:1151-1156.

2. Amanti, A., Potalivo, G., Pelosi, F., Rende, R., \& Cerulli, G., (2010): Randomized prospective study on the use of Eufiss in the prevention of infections in patients treated with external fixation. European journal of inflammation, 8(3), 189-192.

3. Babis, G. C., Evangelopoulos, D. S., Kontovazenitis, P., Nikolopoulos, K., \& Soucacos, P., (2011): High energy tibial plateau fractures treated with hybrid external fixation. Journal of orthopaedic surgery and research, 6(1), 35 .

4. Brereton, V., (2016): Pin site care the rate of local infection. Orthopedic external fixation device: Management \& Care, Journal of Wound care, (1): 9-11. 
5. Checketts R., Otterburn M., \& MacEachern G., (1993): Pin track infection: definition, incidence and prevention. Int J Orthop Trauma, 16-18.

6. Christopher A., \& Raymond W., (2016): A systematicc review of incidence of pin track infections associated with external fixation,Journal of limb lengthening and Reconstruction, Volume 2, Issue (1), 6-16.

7. Ferreira N., \& Marais L., (2012): Prevention and management of external fixator pin track sepsis, Strategies in Trauma and Limb Reconstruction, Volume 7, Issue 2, 67-72.

8. Golubović, I., Ristić, B., Stojiljković, P., Ćirić, M., Golubović, I., Radovanović, Z., \& Najman, S., (2016): Results of open tibial fracture treatment using external fixation. Srpski arhiv za celokupno lekarstvo, 144(5-6), 293299.

9. Ignatavicius, D. D., \& Workman, M. L., (2015): Medical- Surgical Nursing - E-Book: Patient-Centered Collaborative Care. Chapter $51,1062$.

10. Khorais, A., Ebraheim, M., Barakat, A., (2018): Self-Care Program: Quality of Life and Satisfaction among Patients with External Skeletal Fixation. IOSR Journal of Nursing and Health Science, 7(4), 71-83.

11. Laible, C., Earl-Royal, E., Davidovitch, R., Walsh, M., \& Egol, K., (2012): Infection After Spanning External Fixation for High-Energy Tibial Plateau Fractures: Is Pin Site-Plate Overlap a Problem?. Journal of orthopaedic trauma, 26(2), 92-97.

12. Lee, C., Chua, Y., \& Saw, A., (2012): Antimicrobial gauze as a dressing reduces pin site infection: a randomized controlled trial. Clinical Orthopedics and Related Research ${ }^{2}$, 470(2), 610-615.

13. Leonid Solomin, (2013): The Basic Principles of External Skeletal Fixation Using the Ilizarov and orther devices, 2ed, 9.

14. Lioyd, Hilary, Bell, Audrey, Leader \& Maria., (2008): Care of pin sites. Nursing Standard, 22 (33) 44-48.

15. Mahdian, M., Fazel, M., Sehat, M., Khosravi, G., \& Mohammadzadeh, M., (2017): Epidemiological profile of extremity fractures and dislocations in road traffic accidents in Kashan, Iran: a glance at the related disabilities. Archives of bone and joint surgery, Vol.5, no.3, Pp. 186.

16. Matt-Hensrud, N., Severson, M., Hansen, D., \& Holland, D., (2015): A discharge planning program in orthopedics: experiences in implementation and evaluation, Orthopedic Nursing, Wolters Luwer Health; 20 (1): 59-66.

17. Mohammed, R., Atinga, E., Sitati, F., \& Gakuya, E., (2017): Pin tract infection after uniplanar external fixation of open fractures at a national, teaching and referral hospital. East and Central African Journal of Surgery, 22(1), 4248.

18. Moneur, C., (2013): Overview of the musculoskeletal system: Rheumatology organization, Chapter 2,Section A: Clinical foundation. Available at: http://my.clevelandclinic.org/health/diseases_co nditions/hic_musculoskeletal_pain/hic_Normal_ Structure_and_function_of_the_M usculoskeletal_System. Accessed in 18/2/2015.

19. Moola, F., Carli, A., Berry, G., Reindl, R., Jacks, D., \& Harvey, E., (2014): Attempting primary closure for all open fractures: the effectiveness of an institutional protocol. Canadian Journal of Surgery, 57(3), E82.

20. Nikolas H., Kazmers, Austin T., Fragomen \& Rozbruch S.,(2016): Prevention of pin site infection in external fixation: a review of the literature. Strategies in Trauma and Limb Reconstruction, Volume 11, Issue (2), 75-85.

21. Rahşan, Ç., Korkmaz, F., \& ŞAV, Ş., (2014): Effects of two different solutions used in pin site care on the development of infection. Acta Orthop Traumatol Turc, 48(1), 80-85.

22. Ramos, T., Karlsson, J., Eriksson, B., \& Nistor, L., (2013): Treatment of distal tibial fractures with the Ilizarov external fixator-a prospective observational study in 39 consecutive patients. BMC musculoskeletal disorders, 14(1), 30.

23. Singh A., (2016): 'External Fixation Devices Concept and Use', Bone and Spine, viewed 16 January

2017, http://boneandspine.com/externalfixation-devices.

24. Suresh K., Sharma, Jogindra Vati, Indarjit Wali, \& Ramesh Sen (2008): The effect of smoking on pin site infection rate among patients with external skeletal fixation. Nursing and Midwifer y Research Journal, 4, (2),71. 